\title{
GREThA
}

Groupe de Recherche en

Économie Théorique et Appliquée

\section{Sustainable coalitions in the commons}

\author{
LUC DOYEN \\ CNRS, CERSP
}

Jean-Christophe PEREAU

Université de Bordeaux

GREThA UMR CNRS 5113

\section{Cahiers du GREThA}

$$
\text { n 2009-15 }
$$

\section{GRETHA UMR C NRS 5113}

Université Montesquieu Bordeaux IV

$$
\text { Avenue Léon Duguit - } 33608 \text { PESSAC - FRANCE }
$$

Tel : +33 (0)5.56.84.25.75 - Fax : +33 (0)5.56.84.86.47 - www.gretha.fr 


\title{
Coalitions durables dans les communs
}

\section{Résumé}

Il est bien connu que l'absence de coopération entre plusieurs agents exploitant une ressource renouvelable en accès libre peut conduire à son extinction. Ce papier se propose d'étudier la relation existante entre le nombre potentiel d'exploitant et l'état du stock lorsque les agents sont hétérogènes en termes de coût et qu'ils peuvent former des coalitions. Un modèle bio-économique est construit combinant une approche de viabilité et la théorie des jeux afin d'analyser l'impact de contraintes bio-économiques sur l'état et la dynamique de la ressource. Fondée sur la valeur de Shapley, une mesure de la contribution marginale des exploitants à la durabilité de la ressource est définie. Elle montre que la stabilité de la grande coalition est possible pour des montants élevés du stock. En revanche, pour de faibles niveaux, l'exploitant le plus efficace joue le rôle de dictateur.

Mots-clés : ressource renouvelable, durabilité, programmation dynamique, coalition, stratégie maxmin, valeur de Shapley, noyau de viabilité

\section{Sustainable coalitions in the commons}

\begin{abstract}
It is well known that the non-cooperation among agents harvesting a renewable resource is critical for its sustainable management. The present paper gives insights on the complex balance between coalitions structure, resource state or dynamics and agents' heterogeneity to avoid bio-economic collapses. A model bringing together coalition games and a viability approach is proposed to focus on the compatibility between bioeconomic constraints and an exploited common stock dynamics. It is examined to what extent cooperation promotes sustainability. Based on the Shapley value, a measure of the marginal contribution of the users to the sustainability of the resource is proposed. It suggests that the stability of the grand coalition occurs for large enough stocks. By contrast, for lower levels of resource, the most efficient user plays the role of a dictator.
\end{abstract}

Keywords: renewable resource, dynamic game, coalition, maxmin strategy, shapley value, viability kernel

JEL : Q20

Reference to this paper: Luc Doyen, Jean-Christophe Pereau, "Sustainable coalitions in the commons", Working Papers of GREThA, n 2009-15 http://ideas.repec.org/p/grt/wpegrt/200915.html. 


\title{
Sustainable coalitions in the commons
}

\author{
L. Doyen ${ }^{\mathrm{a}}$, Jean-Christophe Pereau ${ }^{\mathrm{b}}$ \\ ${ }^{a}$ CNRS, CERSP, Muséum National d'Histoire Naturelle, 55 rue Buffon, 75005 Paris \\ Cedex, France. Email: lucdoyen@mnhn.fr \\ ${ }^{b}$ GRETHA - Groupe de recherche en Économie Théorique et Appliquée, UMR 5113 \\ CNRS - Université Montesquieu Bordeaux IV. Email: \\ jean-christophe.pereau@u-bordeaux4.fr
}

\begin{abstract}
It is well known that the non-cooperation among agents harvesting a renewable resource is critical for its sustainable management. The present paper gives insights on the complex balance between coalitions structure, resource state or dynamics and agents' heterogeneity to avoid bio-economic collapses. A model bringing together coalition games and a viability approach is proposed to focus on the compatibility between bio-economic constraints and an exploited common stock dynamics. It is examined to what extent cooperation promotes sustainability. Based on the Shapley value, a measure of the marginal contribution of the users to the sustainability of the resource is proposed. It suggests that the stability of the grand coalition occurs for large enough stocks. By contrast, for lower levels of resource, the most efficient user plays the role of a dictator.
\end{abstract}

Keywords: renewable resource, dynamic game, coalition, maxmin strategy, shapley value, viability kernel.

JEL: Q20

\section{Introduction}

This paper deals with the cooperation among users harvesting a renewable resource. According to recent studies (MEA, 2005), biodiversity and exploited renewable resources are under extreme pressure worldwide. For instance, three quarters of fish stocks worldwide are maximally exploited or over-exploited (FAO, 2004). Hence sustainability is nowadays a major concern of international agreements and guidelines to fisheries management (ICES, 2004). In this context, exploited biodiversity management involves restoration and conservation objectives, with ecological and economic dimensions including the identification of desirable levels of stocks and profitability from catches. It inevitably raises the question of the number of active potential users of the resource and the way they can cooperate. To avoid possible future collapses of the stocks, catches and rents, we need to determine the conditions under which cooperation can be sustainable. 
Game theory modeling (Kaitala \& Munro, 1995; Kaitala \& Lindroos, 2007) provides some important insights on strategic interaction between users exploiting a renewable resource. In particular, the relationship between the number of active agents and the sustainability of the involved stock has been studied in static non cooperative game by Mesterton-Gibbons (1993) or Sandal \& Steinshamn (2004) in presence of users differing with respect to their efficiency in terms of harvesting cost. These models both show how the larger the stock, higher the number of active players is. MestertonGibbons (1993) derives this result by considering rent maximising users who take into account the stock externality arising from the actions of the other users. Similarly, Sandal \& Steinshamn (2004) investigate another strategic interaction between users relying on a Cournot competition. They also introduce an incumbent agent whose role is to achieve sustainability by setting the resource at its steady state.

The question of coalitions has also received an important attention in the context of renewable resource management. What distinguishes renewable resources coalition game from many other coalition games is that major externalities occur. A particular attention has been paid to coalition issues in fisheries economics (Kaitala \& Lindroos, 1998; Arnason et al., 2000; Burton, 2003; Lindroos, 2004a). The need for the research of cooperative fisheries management arises from the current practice of international negotiations and implementation of multi-country fisheries agreements. In this context, the coalition game theory literature focused on the formation of the coalitions, their stability and the way the benefits of cooperation are shared between the users. Kaitala \& Lindroos (1998) show in a three-player game that there is a partial cooperative equilibrium stock level that is higher than the non-cooperative stock level (Clark, 1980), though lower than the fully cooperative stock level (Clark \& Munro, 1975). Lindroos (2004a) extends these results in a four-player game. In this perspective, of particular interest is the question raised by the stability of the coalition and especially the grand coalition. Hence, Arnason et al. (2000) analyse the case of Atlanto-Scandian herring and points out that Norway is a crucial country for any coalition to be stable. This result is related to Lindroos (2004a) who considers the possibility of veto countries. Using a partition function game as in Bloch (1996) and Finus (2001), Pintassilgo (2003) derives general results regarding the stability of coalition structures in straddling stock fisheries. Kronbak \& Lindroos (2007) predict a stable grand coalition while Lindroos (2004b) points out the connections between safe minimum biological levels and stability of full cooperation. This literature also proposes allocation rules of the cooperation benefits between the members of a coalition (Lindroos, 2004b; Kronbak \& Lindroos, 2007; Li, 1999). These allocations solutions include 
Shapley value (probably the most used), nucleolus and tau-value.

Our paper questions the shape and size of coalitions with respect to sustainable requirements for the exploited renewable resource. Although our work is in direct line with the models of the literature, it gives new insights by considering a dynamic game focusing on viability constraints. Thus our model differs in several ways. First our approach is dynamic in the sense that the analysis is not restricted to steady states and equilibrium yield. Second, a viability viewpoint is adopted to cope with sustainability. The viability (or viable control) approach does not strive to identify optimal or steady state paths, but rather aims at identifying the conditions that allow desirable objectives or constraints to be fulfilled over time, considering both present and future states (Baumgartner \& Quaas, 2009; Bene et al., 2001). As emphasized in DeLara \& Doyen (2008) or Martinet \& Doyen (2007), viability is closely related to the maximin (Rawlsian) approach with respect to intergenerational equity. Viability may also allow for the satisfaction of both economic and environmental constraints and is, in this respect, a multi-criteria approach. Viability analysis has been applied to renewable resources management and especially to fisheries (see, e.g. Bene et al. (2001); Eisenack et al. (2006); Martinet et al. (2007), but also to broader (eco)-system dynamics (Cury et al., 2005; Doyen et al., 2007; Bene \& Doyen, 2008). Relationships between sustainable management objectives and reference points as adopted in the ICES precautionary approach are discussed in DeLara et al. (2007). Here the viability framework allows us to exhibit the conditions under which coalitions can fulfill positive profitability and conservation objectives along time, considering both present and future states of the renewable resource system.

The paper is organized as follows. Section 2 is devoted to the description of the dynamic bio-economic model together with the profitability constraints. Section 3 provides the results related to the shape of the viable coalitions with respect to the level of the resource. The contribution of the agents to the viability is also analyzed using the minimum number of active players and the Shapley value of the game. The last section concludes.

\section{The dynamic model}

The dynamics of a renewable resource stock $x(t) \in \mathbb{R}_{+}$is given by

$$
x(t+1)=f(x(t)-h(t)), \quad t=0,1, \ldots, T,
$$

where catches $h(t)$ occur at the beginning of the period. The natural resource productivity is represented by $f$. We denote by $K$ the capacity charge of 
the resource defined by

$$
K=\sup (x \geq 0, f(x) \geq x) .
$$

We consider that the resource is exploited by $n$ agents, implying an amount of harvest given by

$$
h(t)=\sum_{i=1}^{n} e_{i}(t) x(t)
$$

with $e_{i} \in[0,1]$ standing for the effort (or harvesting mortality) of each agents $i \in\{1, . ., n\}$. Since take-off can not exceed resource stock, a scarcity constraint holds:

$$
0 \leq h(t) \leq x(t)
$$

implying a constraint on the effort

$$
\sum_{i=1}^{n} e_{i}(t) \leq 1
$$

The rent of each agent $i$ is defined by:

$$
\Pi_{i}\left(x(t), e_{i}(t)\right)=p e_{i}(t) x(t)-c_{i} e_{i}(t),
$$

where $c_{i}$ measures the cost per unit of effort and the price $p$ of the resource is assumed to keep constant. The rent is positive for each agent $i$ when the stock is larger than the the zero-rent level (or open access stock) namely

$$
x(t)>x_{i}^{\mathrm{OA}}=\frac{c_{i}}{p} .
$$

We assume that the agents are heterogeneous in the sense that they differ in their cost:

$$
c_{1}<c_{2}<\ldots<c_{n-1}<c_{n},
$$

or equivalently in their open access stocks

$$
x_{1}^{\mathrm{OA}}<x_{2}^{\mathrm{OA}}<\ldots<x_{n-1}^{\mathrm{OA}}<x_{n}^{\mathrm{OA}} .
$$

It is worth noting that two kinds of externalities occur in this game as every agent may alter both the current catches (and rents) of others agents by the scarcity constraint (2) and also the future catches of agents through harvesting and dynamics (1) which impact the stock for the next period.

Sustainability problem:. The dynamic problem that we handle is to determine coalitions $S \subset\{1, \ldots, n\}$, harvesting strategies among the coalition $e_{i}(t), i \in S$ and a stock path $x(t)$ which ensures that the aggregated rent of the agents $i$ belonging to the coalition $S$ remains strictly positive, i.e.:

$$
\sum_{i \in S} \Pi_{i}\left(x(t), e_{i}(t)\right)>0, \quad t=0,1, \ldots, T
$$


Cooperation among a group of players corresponds to the establishment of a management organization with the purpose of managing and protecting the resource stocks jointly. Such a profitability constraint entails the following resource viability requirement captured by the critical bio-economic level $x^{S}$

$$
x(t)>x^{S}=\min _{i \in S} x_{i}^{\mathrm{OA}} .
$$

The present paper intends to give insights on the shape and size of the coalition $S$ regarding the initial value of the stock $x_{0}$, the resource dynamics $f$, the economic context ( $c$ and $p$ ) and these sustainability goals.

Viable states and viability kernel: . To achieve this, we define the viability kernels $\operatorname{Viab}_{S}(t)$ for a given coalition $S$ through backward induction inspired by dynamic programming. First, at the terminal date $T$, we set

$$
\operatorname{Viab}_{S}(T)=\left\{x \mid x>x^{S}\right\}
$$

For any time $t=0,1, \ldots, T-1$, we compute the viability kernel $\operatorname{Viab}_{S}(t)$ at time $t$ from the viability kernel $\operatorname{Viab}_{S}(t+1)$ at time $t+1$ as follows:

$$
\operatorname{Viab}_{S}(t)=\left\{\begin{array}{l|c}
\exists e_{i} \geq 0, \forall i \in S, \sum_{i \in S} \Pi_{i}\left(x, e_{i}\right)>0 \\
x>x^{s} & \begin{array}{c}
\left.x\left(1-\sum_{i \in S} e_{i}-\sum_{j \notin S} e_{j}\right)\right) \in \operatorname{Viab}_{S}(t+1) \\
\forall j \notin S, \forall e_{j} \geq 0 \text { s.t. } \Pi_{j}\left(x, e_{j}\right) \geq 0
\end{array}
\end{array}\right\}
$$

The previous definition stresses the fact that the agents among the coalition cooperate for sustainable profitability goals applying both in the present and the future while the outsiders of the coalition act as singleton and are myopic regarding profitability goals. When the users of the resource cooperate within a coalition, the positive profitability condition holds for the whole coalition. The myopic behavior of the outsiders can encompass several strategies including optimizing, inertial ones which are potentially dangerous and risky for the resource.

A simple game formulation: The previous geometric definition of viability kernels can be associated with the following "'maxmin"' (supinf) functional formulation which points out the "simple" (0 or 1$)$ nature of the game. Let us consider the indicator function $\mathbb{I}_{\operatorname{Viab}_{S}(t)}($.$) defined by:$

$$
\mathbb{I}_{\operatorname{Viab}_{S}(t)}(x)=\left\{\begin{array}{lll}
1 & \text { if } & x \in \operatorname{Viab}_{S}(t) \\
0 & \text { if } & x \notin \operatorname{Viab}_{S}(t) .
\end{array}\right.
$$


Such indicator function $\mathbb{I}_{\operatorname{Viab}_{S}(t)}($.$) turns out to be the solution of the fol-$ lowing maxmin dynamic programming equation:

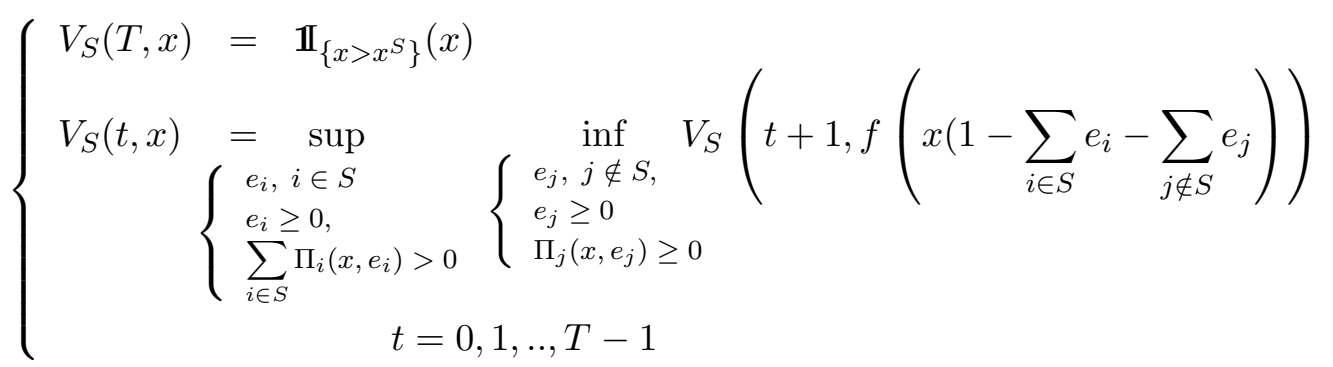

Such a formulation also highlights the asymmetric feature between the goals of outsiders-insiders.

Viable feedbacks: Given a resource state $x$ at time $t$, the viable feedbacks for each coalition $S$ denoted by $e_{S}^{*}(t, x)=\left(e_{i}^{*}(t, x)\right)_{i \in S}$ for time $t<T$ are characterized by

$$
\left\{\begin{array}{l}
e_{i}^{*}(t, x) \geq 0, \forall i \in S, \sum_{i \in S} \Pi\left(x, e_{i}^{*}(t, x)\right)>0 \\
f\left(x\left(1-\sum_{i \in S} e_{i}^{*}(t, x)-\sum_{j \notin S} e_{j}\right)\right) \in \operatorname{Viab}_{S}(t+1) \\
\forall j \notin S, \forall e_{j} \geq 0 \text { s.t. } \Pi_{j}\left(x, e_{j}\right) \geq 0
\end{array}\right.
$$

Such a viable feedback effort $e_{S}^{*}(t, x)$ exists as soon as the resource state $x$ belongs to the viability kernel $\operatorname{Viab}_{S}(t)$. Of course the design of such viable efforts require the knowledge of the whole sequence of viability kernels.

\section{Results}

Hereafter, the stock productivity $f: \mathbb{R}_{+} \rightarrow \mathbb{R}_{+}$is assumed to be continuously increasing $f^{\prime}>0$ and to satisfy $f(0)=0$. We also assume that the open-access stocks $x_{i}^{\mathrm{OA}}$ lie in the part where the resource growths in the following sense:

$$
\left.\left[x_{1}^{\mathrm{OA}}, x_{n}^{\mathrm{OA}}\right] \subset\right] 0, K[=\{x \geq 0, f(x)>x\}
$$

\subsection{Viable coalitions and states:}

Let us first identify the viable stocks through the computation of the viability kernels for every coalition.

Theorem 1 The viability kernels at time $t(t<T)$ are

- $\operatorname{Viab}_{S}(t)=\emptyset$ if $1 \notin S$

- $\left.\operatorname{Viab}_{\{1, \ldots, n\}}(t)=\right] x_{1}^{\mathrm{OA}},+\infty[$

- $\left.\operatorname{Viab}_{\{1, \ldots, j\}}(t)=\right] x_{1}^{\mathrm{OA}}, x_{j+1}^{\mathrm{OA}}[$ for $j<n$ 
- $\operatorname{Viab}_{S}(t)=\operatorname{Viab}_{\widetilde{S}}(t)$ for $\widetilde{S}=\cup_{i}(\{1 \ldots i\} \subset S)$

The proofs of Theorem 1 are exposed within the appendix ${ }^{1}$. Theorem 1 identifies what are the size and the composition of the viable coalition of users with respect to the stock of the resource. To illustrate this, consider the Table 1 where we can distinguish the viability kernels in the case with three players $n=3$.

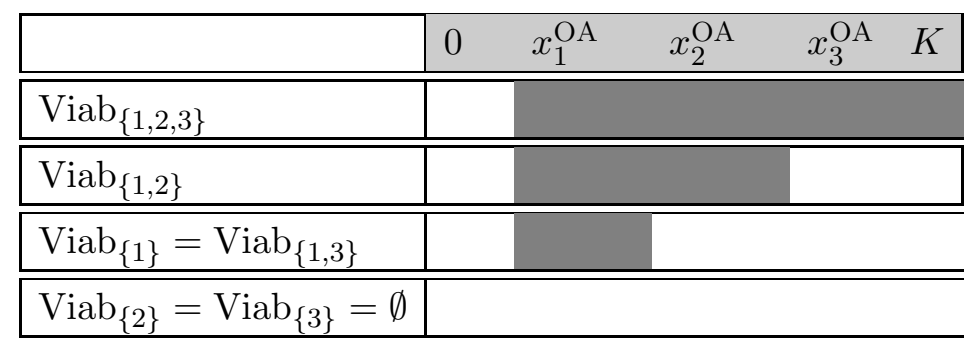

Table 1: Viability kernels with three players $n=3$.

The tragedy of open-access revisited: It turns out that cooperation promotes the viability as the higher cooperation between users is, the larger is the viability domain. In particular, the grand coalition $N=\{1,2,3\}$ (social viability) corresponds to the largest viability kernel $] x_{1}^{\mathrm{OA}},+\infty[$. By contrast, the smallest viable coalition occurs with singletons. In particular, viability vanishes for singletons $S=\{2\}$ or $S=\{3\}$ since both viability kernels $\operatorname{Viab}_{\{2\}}(t)$ and $\operatorname{Viab}_{\{3\}}(t)$ are empty. Another significant viable coalition is formed by agents 1 and 2. However viability is reduced in this partial cooperation case as $\operatorname{Viab}_{\{1,2\}}(t)$ is strictly contained in $\operatorname{Viab}_{\{1,2,3\}}(t)$. Of interest is the fact that the coalition formed by players 1 and 3 is equivalent to singleton $\{1\}$ emphasizing that the role of player 3 is minor in this case. The Shapley value developed in subsection 3.5 will highlight this idea by computing viability contribution values for the different players.

Agent 1 is a veto player:. These kernels also emphasize that player 1 is a veto player as its presence is always required for the cooperation to be viable. In other words, as soon as the most efficient user 1 is not a member of the coalition, the associated viability kernels are empty. In particular, the only viable singleton is $S=\{1\}$. Again, the Shapley value developed in subsection 3.5 will give more insights on this veto and dictatorship situations.

\footnotetext{
${ }^{1}$ Note that all the results could be extended to the infinite horizon case since it turns out that the viability kernels do not depend on time.
} 


\subsection{A focus on the grand coalition (social viability):}

Coordination promotes the viability as the grand coalition $N=\{1, \ldots, n\}$ corresponds to the largest viability kernel $] x_{1}^{\mathrm{OA}},+\infty[$. Such a configuration allows to recover several well-known cases of bio-economic states. In particular it turns out that the maximum economic states $x^{\mathrm{MEY}}$ belongs to the viability kernel $\operatorname{Viab}_{N}$ of the grand coalition. These maximum economic states $x^{\mathrm{MEY}}$ actually depends on the agents $i$ features since they rely on the maximization of profits which are associated to costs $c_{i}$ as follows:

$$
\left(x_{i}^{\mathrm{MEY}}, e_{i}^{\mathrm{MEY}}\right) \in \operatorname{Arg}\left\{\begin{array}{c}
\max _{(x, e)} \\
f(x(1-e))=x
\end{array} \Pi_{i}(x, e) .\right.
$$

Corollary 1 Maximum economic states $x_{i}^{\mathrm{MEY}}>0$ are viable for the grand coalition: $x_{i}^{\mathrm{MEY}} \in \operatorname{Viab}_{N}(t)$ for any $i \in N$.

The proof, exposed in AppendixA.5, relies on the idea that the maximum economic equilibrium is always larger than the open-access equilibrium.

Similarly the non cooperative equilibrium $x^{N C}$ in the sense of MestertonGibbons (1993) belongs to the viability kernel $\operatorname{Viab}_{N}$ of the grand coalition. If it exists, such non cooperative equilibrium $x^{N C}$ is the solution of the problem:

$$
\Pi_{i}\left(x^{N C}, e_{i}^{N C}\right)=\left\{\begin{array}{c}
\max _{e_{i} \geq 0} \\
f\left(x^{N C}\left(1-\sum_{i} e_{i}\right)\right)=x^{N C}
\end{array} \Pi_{i}\left(x^{N C}, e_{i}\right), i=1, . ., n\right.
$$

Corollary 2 Non cooperative equilibrium $x^{N C}>0$ is viable for the grand coalition: $x^{N C} \in \operatorname{Viab}_{N}(t)$.

Again the proof relies on the idea that the non cooperative equilibrium $x^{N C}$ is always larger than the open-access equilibria $x_{i}^{\mathrm{OA}}$ and consequently $x_{1}^{\mathrm{OA}}$. However this assertion sounds counterintuitive as a non cooperative equilibrium is not a good candidate for a full cooperation. Actually, this non cooperative equilibrium $x^{N C}$ has some cooperative feature because it is a steady state for which the agents implicitly agree on setting the resource at some stationary (and thus sustainable or viable) level.

\subsection{Minimum number of players}

Given a stock level $x$, we define by $n^{*}(x)$ the minimum number of players in a viable coalition by:

$$
n^{*}(x)=\min \left(|S| \mid x \in \operatorname{Viab}_{S}(0)\right)
$$

where $|S|$ stands for the cardinal of the coalition $S$. 


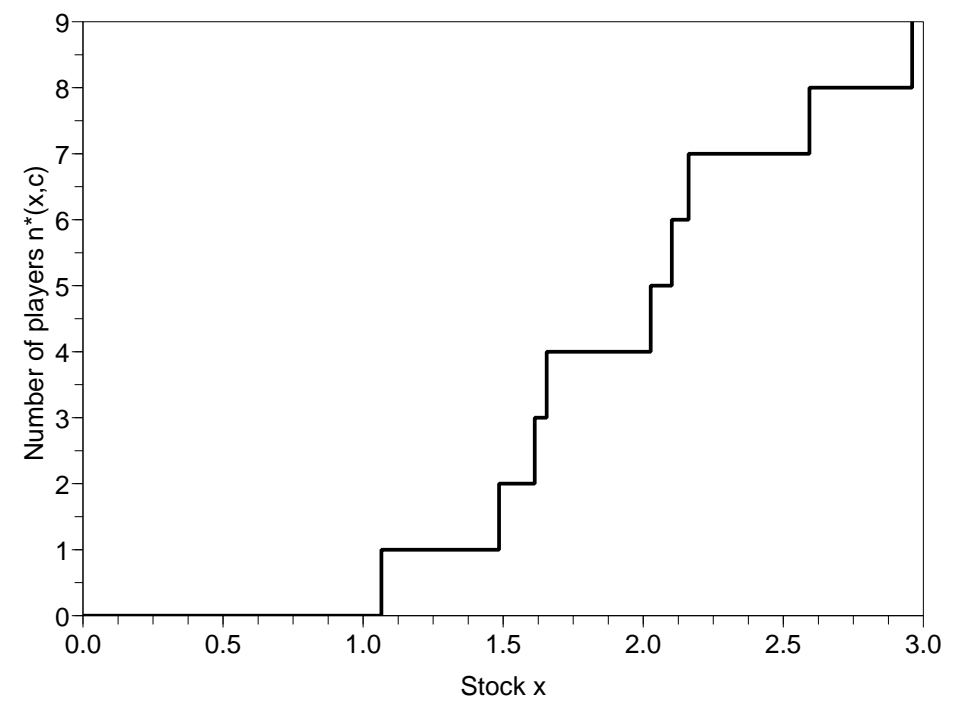

Figure 1: A numerical example of minimal players $n^{*}(x)$ for a viable coalition $S$.

Using Theorem 1, we derive the following condition

$$
n^{*}(x)=\min \left(j \mid x_{1}^{\mathrm{OA}}<x<x_{j+1}^{\mathrm{OA}}\right\}
$$

which is illustrated by the stepwise increasing function displayed in Figure 3.3. This minimum number of active players in a coalition in our dynamic framework is a generalization of the steady state participation condition of Mesterton-Gibbons (1993). It is worth noting that our approach expands this result since steady states are particular cases of viability (DeLara \& Doyen (2008)).

Let us emphasize that the number of viable players increases with stock. In particular, this suggests that the grand coalition is stable whenever the stock is large enough. This assertions is examined in detail in section 3.5 through the shapley value.

\subsection{Viable efforts for the viable coalitions:}

The next step of the analysis is to exhibit the viable effort of the members of the coalition. Applying the "dynamic programming" characterization of viable feedbacks displayed in (3), we deduce a characterization of the viable feedbacks $e_{S}^{*}(t, x)$ for a given coalition $S$. As shown in proof AppendixA from equation (A.1), we obtain

Theorem 2 The viable feedbacks $e_{S}^{*}(t, x)=\left(e_{i}^{*}(t, x)\right)_{i \in S}$ for a coalition $S$ and any stock $x$ in $\left.\operatorname{Viab}_{S}(t)=\right] x_{1}^{\mathrm{OA}}, x_{j+1}^{\mathrm{OA}}[$ are solutions of the linear con- 
straints

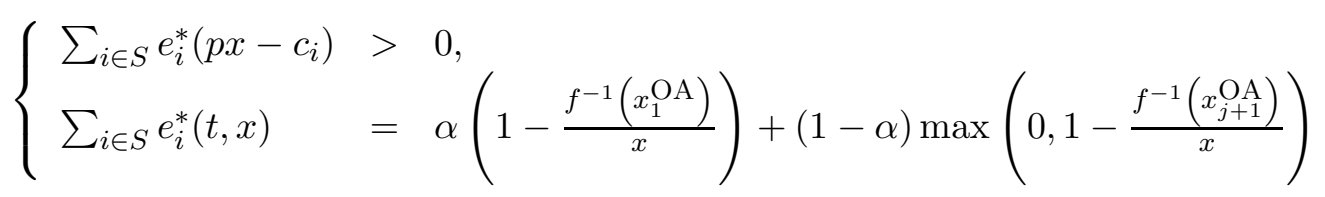

where $0<\alpha<1$.

Note that several catch efforts can satisfy such linear inequalities and consequently a flexibility occurs in the decision process. Among these viable choices, one can favor efficient or conservative rules or different trade-offs between ecological or economic performances.

In order to prevent the outsiders to collapse the resource and the rents, the coalition has to manage the resource in a way that the outsiders become passive. The coalition has to maintain the resource in its viability domain to guarantee its sustainability. Actually, the coalition achieves this by neutralizing the outsiders in a sustainable way. This neutralization occurs by avoiding every profitability for outsiders and more specifically by maintaining the resource below open-access levels for outsiders. In such a context, since all the outsiders of the coalition are passive, the coalition does not have to take into account that it can play against either a coalition formed by the outsiders or against individual outsiders.

\subsection{Marginal contribution to viability}

We define a Shapley measure of the marginal contribution of agents $i$ belonging to a coalition $S$ to the viability kernel as

$$
\mathrm{Sh}_{i}(x)=\sum_{i \in S \subseteq N} \frac{(|S|-1) !(n-|S|) !}{n !}\left(\mathbb{I}_{\operatorname{Viab}_{S}}(x)-\mathbb{1}_{\operatorname{Viab}_{S \backslash\{i\}}}(x)\right)
$$

Applying for instance Lemma 2 (p 362) in Aubin (2007) for simple games, we obtain the following characterization of Shapley value:

Theorem 3 For $x \in] x_{j}^{\mathrm{OA}}, x_{j+1}^{\mathrm{OA}}[$, we have

$$
\operatorname{Sh}_{i}(x)=\left\{\begin{array}{lll}
\frac{1}{n^{*}(x)} & \text { for } & i \leq j \\
0 & \text { for } & i>j
\end{array}\right.
$$

Consequently, the Shapley value captures the fact that whenever the users are active, they contribute positively and to the same amount to the sustainability of the resource. By contrast, passive players contribute for nothing to the sustainability of the resource. Our approach differs from the cooperative coalition games in which the Shapley value is used to compute the shares of the cooperative rent inside the members of the coalition who have created the surplus. Our measure of the marginal contribution to the viability kernel is more qualitative and relies on the ability of players 


\begin{tabular}{|c|ccccccc|}
\hline Agents $i \backslash$ Stock $x$ & 0 & & $x_{1}^{\mathrm{OA}}$ & \multicolumn{2}{c|}{$x_{2}^{\mathrm{OA}}$} & \multicolumn{2}{c|}{$x_{3}^{\mathrm{OA}}$} \\
\hline \hline agent 1 & $\mid$ & 0 & & $100 \%$ & $50 \%$ & $33 \%$ \\
\hline agent 2 & $\mid$ & 0 & & 0 & $50 \%$ & $33 \%$ \\
\hline agent 3 & $\mid$ & 0 & 0 & 0 & $33 \%$ \\
\hline
\end{tabular}

Table 2: Shapley values $\operatorname{Sh}_{i}(x)$ for $n=3$ players

to maintain a safe exploitation of the resource. Applied to our 3 players' example, it gives the table 2 .

Therefore, the value of the marginal contribution $\mathrm{Sh}_{i}$ of each user determines whether his participation to a coalition is required or not. Note also that in any case, an equity rule among the active players holds true as the "cake" is shared in $n^{*}(x)$ equal parts. In particular, when the stock is high enough to ensure the active participation of all players, their contributions to the sustainability of the resource are identical. It means that all the agents have the same power to sustain the stock. This situation requires a global cooperation within a coalition. It turns out that the most efficient users cannot displace the less efficient users. At the opposite, when the initial stock is low and lies in the interval $x \in] x_{1}^{\mathrm{OA}}, x_{2}^{\mathrm{OA}}[$, only the most efficient agent and veto player is active and can contribute to the sustainability of the resource. No cooperation with the other agents is required. An intermediate or partial coalition involving an active contribution of player 2 is viable but the veto player 1 has to be always involved as expected.

Corollary 3 Agent 1 is a veto player if $x>x_{1}^{\mathrm{OA}}$.

This corollary directly stems from the fact that $\mathrm{Sh}_{1}(x)>0$ for any $x>x_{1}^{\mathrm{OA}}$.

Corollary 4 Agent 1 is a dictator if $x \in] x_{1}^{\mathrm{OA}}, x_{2}^{\mathrm{OA}}[$

This last result is due to the fact that $\mathrm{Sh}_{1}(x)=1$ for any $\left.x \in\right] x_{1}^{\mathrm{OA}}, x_{2}^{\mathrm{OA}}[=$ $\operatorname{Viab}_{\{1\}}$.

\section{Conclusion}

This paper has analyzed the conditions under which cooperation of active heterogeneous users within coalition is required to promote the bio-economic viability of a renewable resource. We have proposed a dynamic model bringing together coalition games and a viability approach to focus on the compatibility between bio-economic constraints and an exploited common stock dynamics. The model allows first to revisit the tragedy of open-access and the seminal work of Hardin as it is showed to what extent lack of cooperation 
reduces or jeopardize the viability of the whole bio-economic system. Focusing on the grand coalition, it is shown how the usual "sustainable" (steady) states including the maximum economic yield (MEY) are particular cases of viability. We have also determined the minimum number of viable players expanding the equilibrium approach of Mesterton-Gibbons (1993) and Sandal \& Steinshamn (2004) to a more dynamic context. Using Shapley value, we assess the contribution of agent to sustainability pointing out situations of veto or dictator players as in Arnason et al. (2000) or Lindroos (2004a). Such a study stresses the fact that diversification in technologies (ratio costs-catchability) is relevant for high levels of stock while specialization, rationalization and dictatorship situations are well-suited for low resource. This suggests how the grand coalition is stable for large resource levels which reinforces assertions of Pintassilgo (2003); Kronbak \& Lindroos (2007) and Lindroos (2004b).

Acknowledgments: We wish to thank comments and suggestions by the participants at the EAERE2009 conference in Amsterdam (Netherlands). 


\section{AppendixA. Appendix: the proofs}

For sake of clarity, we introduce the following notations and lemmas

- The vector of efforts made by coalition $S_{j}=\{1, \ldots, j\}$ is denoted by

$$
e_{S_{j}}=\left(e_{1}, \ldots, e_{j}\right)
$$

- The simplex of coalition $S_{j}=\{1, \ldots, j\}$ is denoted by $\Delta_{j}$ and defined by

$$
\Delta_{j}=\left\{e_{S_{j}}=\left(e_{1}, \ldots, e_{j}\right) \in \mathbb{R}_{+}^{j}, \sum_{i=1}^{j} e_{i} \leq 1\right\} .
$$

- The set of feasible decisions for coalition $S_{j}=\{1, \ldots, j\}$ is

$$
\mathcal{A}_{j}(x)=\left\{e \in \Delta_{j}, \sum_{i=1}^{j} \Pi_{i}\left(x, e_{i}\right)>0\right\} .
$$

Lemma 1 If $x>x_{1}^{\mathrm{OA}}$ then $m=\inf _{e \in \mathcal{A}_{j}(x)} \sum_{i=1}^{j} e_{i}=0$.

Proof. If $x>x_{1}^{\mathrm{OA}}$ then $\mathcal{A}_{j}(x) \neq \emptyset$. Then pick up some $e=\left(e_{1}, \ldots, e_{j}\right) \in$ $\mathcal{A}_{j}(x)$. First since $e_{i} \geq 0$, it is clear that $\sum_{i=1}^{j} e_{i} \geq 0$ and thus $m \geq 0$. Now assume for a while that $m>0$. It means that for any integer $k \in \mathbb{N}$ there exits a sequence of vector $e^{k} \in \mathcal{A}_{j}(x)$ such

$$
m \leq \sum_{i=1}^{j} e_{i}^{k} \leq m+\frac{1}{k} .
$$

But taking the sequence $e^{k^{\prime}}=\frac{e^{k}}{2}$, we have $e^{k^{\prime}} \in \mathcal{A}_{j}(x)$ and

$$
\sum_{i=1}^{j} e_{i}^{k^{\prime}}=0.5 * \sum_{i=1}^{j} e_{i}^{k} \leq 0.5 *(m+1 / k) .
$$

For k large enough, we claim that $0.5 *\left(m+\frac{1}{k}\right)<m$. Hence $\sum_{i=1}^{j} e_{i}^{k^{\prime}}<m$ and a contradiction occurs.

Lemma $2 \forall x \in] 0, K\left[\right.$, we have $f(x)>x$ and $x>f^{-1}(x)$.

Proof. The first part comes from assumption 4. Since the function $f$ is continuously increasing, it is a bijection and the second part of the lemma is proved. 
AppendixA.1. For the grand coalition $S=N$

At the date $t=T$, we have

$$
\operatorname{Viab}_{N}(T)=\left\{x>x^{N}=x_{1}^{\mathrm{OA}}\right\}
$$

From the very recursive definition, the viability kernel at time $T-1$ reads

$\operatorname{Viab}_{N}(T-1)=\left\{\begin{array}{l|l}x>x_{1}^{\mathrm{OA}}, \exists e \in \Delta_{n} \text { s.t. } & \begin{array}{l}\sum_{i=1}^{n} \Pi_{i}\left(x, e_{i}\right)>0, \\ f\left(x\left(1-\sum_{i=1}^{n} e_{i}\right)\right) \in \operatorname{Viab}_{N}(T)\end{array}\end{array}\right\}$

Thus

$$
\operatorname{Viab}_{N}(T-1)=\left\{x>x_{1}^{\mathrm{OA}}, \sup _{e \in \mathcal{A}_{n}(x)} f\left(x\left(1-\sum_{i=1}^{n} e_{i}\right)\right)>x_{1}^{\mathrm{OA}}\right\}
$$

Since $f$ is increasing, we have using lemma (1)

$$
\begin{aligned}
\sup _{e \in \mathcal{A}_{n}(x)} f\left(x\left(1-\sum_{i=1}^{n} e_{i}\right)\right) & =f\left(x\left(1-\inf _{e \in \mathcal{A}_{n}(x)} \sum_{i=1}^{n} e_{i}\right)\right) \\
& =f(x)
\end{aligned}
$$

Therefore $\operatorname{Viab}_{N}(T-1)=\left\{x>x_{1}^{\mathrm{OA}}, x>f^{-1}\left(x_{1}^{\mathrm{OA}}\right)\right\}$. From the properties of the function $f$ depicted in 4 , we have $\max \left\{x_{1}^{\mathrm{OA}}, f^{-1}\left(x_{1}^{\mathrm{OA}}\right)\right\}=x_{1}^{\mathrm{OA}}$. It yields

$$
\left.\operatorname{Viab}_{N}(T-1)=\right] x_{1}^{\mathrm{OA}},+\infty[
$$

Now let us assume the viability domain for the grand coalition $S=N$ at time $t+1$ is $\operatorname{Viab}_{N}(t+1)=\left\{x>x_{1}^{\mathrm{OA}}\right\}$. From the recursive formulation we have

$$
\operatorname{Viab}_{N}(t)=\left\{x \mid x>x_{1}^{\mathrm{OA}}, \exists e \in \mathcal{A}_{n}(x), f\left(x\left(1-\sum_{i=1}^{n} e_{i}\right)\right)>x_{1}^{\mathrm{OA}}\right\}
$$

Using a similar reasoning, we obtain

$$
\left.\operatorname{Viab}_{N}(t)=\left\{x>x_{1}^{\mathrm{OA}}, f(x)>x_{1}^{\mathrm{OA}}\right\}=\right] x_{1}^{\mathrm{OA}},+\infty[
$$

AppendixA.2. The coalition $S=\{1, \ldots, j\}$.

Let us consider the case the coalition $S$ is formed by agents 1 to $j$, i.e. $S=\{1, \ldots, j\}$.

At the date $t=T$, we have

$$
\operatorname{Viab}_{N}(T)=\left\{x>x^{\{1, \ldots, j\}}=x_{1}^{\mathrm{OA}}\right\}
$$

At time $t=T-1$, we have

$$
\operatorname{Viab}_{\{1, \ldots, j\}}(T-1)=\left\{\begin{array}{l|l}
x>x_{1}^{\mathrm{OA}} & \begin{array}{c}
\exists e \in \mathcal{A}_{j}(x), \forall\left(e_{l}\right)_{l \notin S}, \Pi_{l}\left(x, e_{l}\right) \geq 0 \\
f\left(x\left(1-\sum_{i \in S} e_{i}-\sum_{l \notin S} e_{l}\right)\right)>x_{1}^{\mathrm{OA}}
\end{array}
\end{array}\right\}
$$


We have to specify at this stage what is the behavior of agent $j+1$ which is outside the coalition. We distinguish two cases according to whether player $j+1$ is passive or remains active.

- If $x \in] x_{1}^{\mathrm{OA}}, x_{j+1}^{\mathrm{OA}}$ [ then players $i=j+1, \ldots, n$ become passive because if they aim at having a positive rent their effort are null $e_{i}=0$. Then using lemma (1) the viability condition becomes

$$
\sup _{e \in \mathcal{A}_{j}(x)} f\left(\left(1-\sum_{i=1}^{j} e_{i}\right) x\right)>x_{1}^{\mathrm{OA}} \Rightarrow f(x)>x_{1}^{\mathrm{OA}} .
$$

From lemma (2), we have $x_{1}^{\mathrm{OA}}<x$ which implies $x>f^{-1}\left(x_{1}^{\mathrm{OA}}\right)$. Thus the viability domain is $] x_{1}^{\mathrm{OA}}, x_{j+1}^{\mathrm{OA}}\left[\subset \operatorname{Viab}_{\{1, \ldots, j\}}(T-1)\right.$

- If $x \geq x_{j+1}^{\mathrm{OA}}$, the stock of the resource is too high to ensure a positive rent for the coalition $S=\{1, \ldots, j\}$ whatever the effort played by player $j+1, . ., n$. Indeed, in that case a feasible reply of player $j+1$ against the coalition $S=\{1, \ldots, j\}$ is to harvest $e_{j+1}=1-\sum_{i=1}^{j} e_{i} \geq 0$ since it induces $\Pi_{j+1}=e_{j+1}\left(p x-c_{j+1}\right) \geq 0$. Such a catch strategy entails the extinction of the resource as $f\left(x\left(1-\sum_{i=1}^{j} e_{i}\right)-e_{j+1}\right)=$ $f(0)=0$. Therefore in that case $\left[x_{j+1}^{\mathrm{OA}}, \infty\left[\cap \operatorname{Viab}_{\{1, \ldots, j\}}(T-1)=\emptyset\right.\right.$.

Thus $] x_{1}^{\mathrm{OA}}, x_{j+1}^{\mathrm{OA}}\left[=\operatorname{Viab}_{\{1, \ldots, j\}}(T-1)\right.$.

Now let us assume the viability domain for the coalition $S=\{1, \ldots, j\}$ at time $t+1$ is $\left.\operatorname{Viab}_{\{1, \ldots, j\}}(t+1)=\right] x_{1}^{\mathrm{OA}}, x_{j+1}^{\mathrm{OA}}[$. From the recursive formulation we have

$$
\operatorname{Viab}_{\{1, \ldots, j\}}(t)=\left\{\begin{array}{cc}
x>x_{1}^{\mathrm{OA}} & \text { s.t. } \exists e \in \mathcal{A}_{j},\left(e_{l}\right)_{l \notin S}, \Pi_{l}\left(x, e_{l}\right) \geq 0 \\
& \left.f\left(x\left(1-\sum_{i} e_{i}\right)\right) \in\right] x_{1}^{\mathrm{OA}}, x_{j+1}^{\mathrm{OA}}[
\end{array}\right\}
$$

Again we have to distinguish two cases:

- If $x \geq x_{j+1}^{\mathrm{OA}}$, the stock of the resource is too high to ensure a positive rent for the coalition $S=\{1, \ldots, j\}$ whatever the effort played by player $j+1$. Indeed, in that case a feasible reply of player $j+1$ against the coalition $S=\{1, \ldots, j\}$ is to harvest $e_{j+1}^{*}=1-\sum_{i=1}^{j} e_{i}$ for any $e \in \mathcal{A}_{j}(x)$. Such a catch strategy entails the extinction of the resource as $\left.f\left(x\left(1-\sum_{i=1}^{j} e_{i}\right)\right)=f(0)=0 \notin\right] x_{1}^{\mathrm{OA}}, x_{j+1}^{\mathrm{OA}}[$. Therefore in that case $\left[x_{j+1}^{\mathrm{OA}}, \infty\left[\cap \operatorname{Viab}_{\{1, \ldots, j\}}(t)=\emptyset\right.\right.$.

- If $x<x_{j+1}^{\mathrm{OA}}$, player $j+1$ becomes passive because if he aims at having a positive rent its effort is null $e_{j+1}=0$. Then using the viable feedbacks 
displayed in (3), the global viability effort of the coalition is such that

$$
\begin{aligned}
x_{1}^{\mathrm{OA}} & <f\left(\left(1-\sum e_{i}^{*}(t, x)\right) x\right)<x_{j+1}^{\mathrm{OA}} \\
f^{-1}\left(x_{1}^{\mathrm{OA}}\right) & <\left(1-\sum e_{i}^{*}(t, x)\right) x<f^{-1}\left(x_{j+1}^{\mathrm{OA}}\right) \\
\frac{f^{-1}\left(x_{1}^{\mathrm{OA}}\right)}{x} & <1-\sum e_{i}^{*}(t, x)<\frac{f^{-1}\left(x_{j+1}^{\mathrm{OA}}\right)}{x} \\
1-\frac{f^{-1}\left(x_{j+1}^{\mathrm{OA}}\right)}{x} & <\sum e_{i}^{*}(t, x)<1-\frac{f^{-1}\left(x_{1}^{\mathrm{OA}}\right)}{x}
\end{aligned}
$$

The RHS of the inequality is positive since from lemma (2) we have $x>x_{1}^{\mathrm{OA}}>f^{-1}\left(x_{1}^{\mathrm{OA}}\right)$. However we have to take into account that the LHS can be negative, it implies that viability effort takes the form

$$
\sum_{i \in S} e_{i}^{*}(t, x)=\alpha\left(1-\frac{f^{-1}\left(x_{1}^{\mathrm{OA}}\right)}{x}\right)+(1-\alpha) \max \left(0,1-\frac{f^{-1}\left(x_{j+1}^{\mathrm{OA}}\right)}{x}\right)
$$

with $0<\alpha<1$

AppendixA.3. The coalition $S$ such that $1 \notin S$ :

At the date $t=T$, we have $\operatorname{Viab}_{S}(T)=\left\{x>x^{S}\right\}$ with $x^{S}>x_{1}^{\mathrm{OA}}$.

At time $t=T-1$, we deduce

$$
\operatorname{Viab}_{S}(T-1)=\left\{x>x^{S} \mid \begin{array}{c}
\exists e \in \mathcal{A}_{S}, \forall\left(e_{l}\right)_{l \notin S}, \Pi_{l}\left(x, e_{l}\right) \geq 0 \\
f\left(x\left(1-e_{1}-\sum_{i \in S} e_{i}-\sum_{l \neq 1, l \notin S} e_{l}\right)\right)>x^{S}
\end{array}\right\}
$$

Consider $x>x^{S}>x_{1}^{\mathrm{OA}}$ and assume for a while that there exists a relevant $e=\left(e_{i}\right)_{i \in S} \in \mathcal{A}_{S}$. Set the effort of player 1 to $e_{1}=1-\sum_{i \in S} e_{i} \geq 0$ and the effort of other players $l$ outside the coalition to zero $e_{l}=0$. The strategy of outsiders $l \neq 1$ is admissible as their profit $\Pi_{l}\left(x, e_{l}\right)=e_{l}\left(p x-c_{l}\right)=0$ is zero. The strategy of outsider 1 is also admissible as $x>x_{1}^{\mathrm{OA}}=\frac{c_{1}}{p}$ and its profit satisfies $\Pi_{1}\left(x, e_{1}\right)=e_{1}\left(p x-c_{1}\right) \geq 0$. However with such a strategy, the dynamics of the stock collapses as

$$
f\left(x\left(1-e_{1}-\sum_{i \in S} e_{i}-\sum_{l \neq 1, l \notin S} e_{l}\right)\right)=f(0)=0<x^{S}
$$

which leads to a contradiction. Consequently $\operatorname{Viab}_{S}(T-1)=\emptyset$. Therefore by backward induction $\operatorname{Viab}_{S}(t)=\emptyset$ for $t<T$.

AppendixA.4. The coalition $\widetilde{S}$ such that $\operatorname{Viab}_{S}(t)=\operatorname{Viab}_{\widetilde{S}}(t)$ for $\widetilde{S}=\cup_{i}(\{1 \ldots i\} \subset S)$

We assume that $1 \in S$. Let us write $S=\widetilde{S} \cup S^{+}$where $\widetilde{S}=\left\{1, \ldots, j^{*}\right\}$.

At the date $t=T$, the equality holds true since

$$
\operatorname{Viab}_{S}(T)=\left\{x>x_{1}^{\mathrm{OA}}\right\}=\operatorname{Viab}_{\widetilde{S}}(T)
$$


At time $t=T-1$, we know that $\left.\operatorname{Viab}_{\widetilde{S}}=\right] x_{1}^{\mathrm{OA}}, x_{j^{*}+1}^{\mathrm{OA}}[$.

First pick up some $x \in \operatorname{Viab}_{\widetilde{S}}$. Then there exists a strategy $e_{\widetilde{S}} \in \mathcal{A}_{\widetilde{S}}$ such that for all outsider $l \in N \backslash \widetilde{S}$ for every choice $e_{l}$ ensuring positive rent $\Pi_{l} \geq 0$, we have

$$
f\left(x\left(1-\sum_{i \in S} e_{i}-\sum_{l \notin S} e_{l}\right)\right) \in \operatorname{Viab}_{\widetilde{S}}(T) .
$$

Let us derive the viable strategy $e_{S}^{\prime}$ for the coalition $S$ from the viable strategy $e_{\widetilde{S}}^{\prime}$ for the coalition $\widetilde{S}$ as follows:

$$
e_{i}^{\prime}=\left\{\begin{array}{lll}
e_{i} & \text { if } & i \in \widetilde{S} \\
0 & \text { if } & i \in S^{+}
\end{array}\right.
$$

It turns out that

- $e_{S}^{\prime} \in \mathcal{A}_{S}$

- for all outsider $l \in N \backslash S$, for every choice $e_{l}$ ensuring a positive rent $\Pi_{l} \geq 0$, we have

$$
f\left(x\left(1-\sum_{i \in S} e_{i}^{\prime}-\sum_{l \notin S} e_{l}\right)\right) \geq f\left(x\left(1-\sum_{i \in S} e_{i}-\sum_{l \notin S} e_{l}\right)\right) \in \operatorname{Viab}_{\widetilde{S}}(T)=\operatorname{Viab}_{S}(T) .
$$

We deduce that $x \in \operatorname{Viab}_{S}(T-1)$.

Now pick some $x \in \operatorname{Viab}_{S}(T-1)$ and let us prove that $\left.x \in\right] x_{1}^{\mathrm{OA}}, x_{j^{*}+1}^{\mathrm{OA}}[$. Assume for a while that $x \geq x_{j^{*}+1}^{\mathrm{OA}}$. Then whatever feasible strategy of the coalition $e_{S} \in \mathcal{A}_{S}$ is, a feasible reply of player $j^{*}+1$ against the coalition $S$ is to harvest $e_{j^{*}+1}=1-\sum_{i \in S} e_{i} \geq 0$ since it induces to $\Pi_{j^{*}+1}=e_{j^{*}+1}(p x-$ $\left.c_{j^{*}+1}\right) \geq 0$. Such a catch strategy entails the extinction of the resource as $f\left(x\left(1-\sum_{i=1}^{j^{*}} e_{i}-e_{j^{*}+1}\right)\right)=f(0)=0<x^{S}$. Consequently we derive a contradiction.

Therefore we obtain the equality $\operatorname{Viab}_{S}(T-1)=\operatorname{Viab}_{\widetilde{S}}(T-1)=$ ]$x_{1}^{\mathrm{OA}}, x_{j^{*}+1}^{\mathrm{OA}}[$

Similar backward induction reasonings allow to generalize the previous result at any time $t<T$.

\section{AppendixA.5. Proof of corollary 1}

Proof. Assume for a while that $0<x_{i}^{\mathrm{MEY}} \notin \operatorname{Viab}_{N}$. Then $x_{i}^{\mathrm{MEY}} \leq x_{1}^{\mathrm{OA}} \leq$ $x_{i}^{\mathrm{OA}}$. Thus $\Pi_{i}\left(x_{i}^{\mathrm{MEY}}, e_{i}^{\mathrm{MEY}}\right)=p e_{i}^{\mathrm{MEY}}\left(x_{i}^{\mathrm{MEY}}-x_{i}^{\mathrm{OA}}\right)=0$ with $e_{i}^{\mathrm{MEY}}=0$. Consequently, $x_{i}^{\mathrm{MEY}}=f\left(x_{i}^{\mathrm{MEY}}\right)$. As $x_{i}^{\mathrm{MEY}} \leq x_{1}^{\mathrm{OA}} \leq x_{i}^{\mathrm{OA}} \leq K$, by assumption (4), we deduce that $x=0$ which is contradictory. 
Arnason, R., Magnusson, G. and Agnarsson, S. 2000. The Norwegian SpringSpawning Herring Fishery: A Stylized Game Model, Marine Resource Economics 15, 293-319.

Aubin J.P. 2007. Mathematical methods of game and economic theory, revised version, Dover.

Baumgärtner S. and Quaas M. F. 2009. Ecological-economic viability as a criterion of strong sustainability under uncertainty, Ecological Economics, 68, 7, 2008-2020.

Bene, C. and Doyen, L., 2008. Contribution values of biodiversity to ecosystem performances: A viability perspective. Ecological Economics 68, 1423.

Béné C., Doyen, L and Gabay D. 2001. A viability analysis for a bioeconomic model, Ecological Economics, 36, 385-396.

Bloch F. 1996. Sequential Formation of Coalitions in Games with Externalities and Fixed Payoff Division, Games and Economic Behavior, 14, 90-123.

Burton P.S. 2003. Community enforcement of fisheries effort restriction. Journal of Environmental Economics and Management 45 (2), 474-491.

Clark, C. 1980. Restricted Access to Common-Property Fishery Resources: A Game-Theoretic Analysis, Dynamic Optimisation and Mathematical Economics (Liu, Pan-Tai, ed.), Plenum Press, New York, 117-132.

Clark, C. and Munro, G. 1975. The Economics of Fisheries and Modern Capital Theory: A Simplified Approach, Journal of Environmental Economics and Management 2, 92-106.

Cury, P., Mullon, C., Garcia, S., and Shannon, L. J. 2005. Viability theory for an ecosystem approach to fisheries. ICES Journal of Marine Science, $62(3), 577-584$.

DeLara, M. and Doyen, L. 2008. Sustainable management of natural resources: mathematical models and methods. Springer.

M. DeLara, Doyen L., Guilbaud, T. and Rochet, M.J, 2007, Is a management framework based on spawning-stock biomass indicators sustainable? A viability approach, ICES J. Marine Science, 64, 761 - 767.

Doyen, L., DeLara, M., Ferraris, J., and Pelletier, D. 2007. Sustainability of exploited marine ecosystems through protected areas: a viability model and a coral reef case study. Ecological Modelling, 208(2-4), 353-366. 
FAO 2004. The state of World Fisheries and Aquaculture. FAO technical Guidelines for Responsible Fisheries 4, Sup 2.

Eisenack, K., Sheffran, J. and Kropp, J. 2006. The Viability Analysis of Management Frameworks for fisheries. Environmental modelling and assessment, 11(1), 69-79.

Finus, M. 2001. Game Theory and International Environmental Cooperation. Edward Elgar: Cheltenham.

Garcia, S. and Grainger, J.R. 2005, Gloom and doom? The future of marine capture fisheries. Phil. Trans. R. Soc B., 360, 21-46

ICES. 2004. Report of the ICES Advisory Committee on Fishery Management and Advisory Committee on Ecosystems. ICES Advices, 1, 1544p.

Kaitala, V. and Munro, G.R. 1995. The economic management of high seas fishery resources: Some game theory aspects. In C. Carraro and J.A. Filar (eds.). Annals of the International Society of Dynamics Games: Control and Game-Theoretic Models of the Environment, Birkhauser, 299-318, Birkhauser, Boston.

Kaitala, V. and Lindroos, M. 1998. Sharing the benefits of cooperation in high sea fisheries: a characteristic function game approach. Natural Resource Modeling 11, 275-299.

Kaitala, V. and Lindroos, M. 2007. Game Theoretic Applications to Fisheries, Handbook of Operations Research in Natural Resources, Springer, vol 99 Ed by A. weintraub et al, 201-215.

Kronbak L.G and Lindroos, M. 2007. Sharing Rules and Stability in Coalition Games with Externalities, Marine Resource Economics, 22, 137-154.

Li, E. 1999. Cooperative High-Seas Straddling Stock Agreement as a Characteristic Function Game, Marine Resource Economics, 13, 247-258.

Lindroos, M. 2004a. Restricted coalitions in the management of regional fisheries organizations. Natural Resource Modeling, 17, 45-70.

Lindroos, M. 2004b. Sharing the benefits of cooperation in the Norvegian spring-spawning herring fishery. International Game Theory Review, 6(1), $35-53$.

Martinet, V. and Doyen, L. 2007. Sustainable management of an exhaustible resource: a viable control approach. Journal of Resource and Energy Economics, 29 (1), 17-39. 
Martinet, V., Thébaud, O., and Doyen, L. 2007. Defining viable recovery paths toward sustainable fisheries. Ecological Economics, 64 (2), 411-422.

Millenium Ecosystem Assessment. 2005. Ecosystems and human well-being, Island Press, Washington, DC.

Mesterton-Gibbons, M. 1993. Game-theoretic Resource modeling, Natural Resource Modeling 7, 93-146.

Pintassilgo, P. 2003. A Coalition Approach to the Management of High Seas Fisheries in the Presence of Externalities. Natural Resource Modeling, 16(2), 175-197.

Sandal, L. and Steinshamn, S. 2004. Dynamic Cournot-competitive harvesting of a common pool resource, Journal of Economic Dynamics and Control 28, 1781-1799. 


\title{
Cahiers du GREThA Working papers of GREThA
}

\section{GREThA UMR CNRS 5113}

\author{
Université Montesquieu Bordeaux IV \\ Avenue Léon Duguit \\ 33608 PESSAC - FRANCE \\ Tel : +33 (0)5.56.84.25.75 \\ Fax : +33 (0)5.56.84.86.47
}

www.gretha.fr

\section{Cahiers du GREThA (derniers numéros)}

2008-26 : AMABLE Bruno, LUNG Yannick, The European Socio-Economic Models of a Knowledge-based society. Main findings and conclusion

2008-27 : MAROUANE Alaya, NICET-CHENAF Dalila, ROUGIER Eric, The law of growth and attraction: an endogenous model of absorptive capacities, FDI and income for MENA countries

2008-28 : OLTRA Vanessa, Environmental innovation and industrial dynamics: the contributions of evolutionary economics

2009-01 : MONTALBAN Matthieu, L'influence de la financiarisation sur les modèles productifs dans l'industrie pharmaceutique: domination et contradictions de la conception du contrôle blockbuster

2009-02 : CARAYOL Nicolas, LAHATTE Agenor, Dominance relations and universities ranking

2009-03 : PETIT Emmanuel, Emotions et décision économique dans le jeu de l'ultimatum

2009-04 : BLANCHETON Bertrand, JEGOUREL Yves, Les fonds souverains : un nouveau mode de régulation du capitalisme financier?

2009-05 : OLTRA Vanessa, KEMP René, DE VRIES Frans P., Patents as a Measure for EcoInnovation

2009-06 : MOYES Patrick, Mesurer les inégalités économiques

2009-07 : CARAYOL Nicolas, CASSI Lorenzo, Who's Who in Patents. A Bayesian approach

2009-08 : FRIGANT Vincent, La chaîne de valeur de l'industrie automobile est-elle soluble dans des pratiques socialement responsables?

2009-09 : ROUILLON Sébastien, Un nouveau mécanisme décentralisant les équilibres de Lindahl

2009-10 : PETIT Emmanuel, Does indignation lead to generosity? An experimental investigation

2009-11 : KECHIDI Med, TALBOT Damien, Réseau de proximité et gestion des interactions techniques et organisationnelles : les firmes pivots de l'aéronautique

2009-12 : DOUAI Ali, MONTALBAN Matthieu, Institutions and the environment: the case for $a$ historical political economy

2009-13 : NICET-CHENAF Dalila, ROUGIER Eric, FDI and growth: A new look at a still puzzling issue

2009-14 : NICET-CHENAF Dalila, ROUGIER Eric, Human capital and structural change: how do they interact with each other in growth?

2009-15 : DOYEN Luc, PERREAU Jean-Christophe, Sustainable coalitions in the commons 